\title{
What Next After Metformin? Guidelines and Indian Context
}

\author{
H B Chandalia1* , Suresh Damodharan², NG Sastry ${ }^{3}$, Vijay Negalur ${ }^{4}$ and Shital Sarda ${ }^{5}$ \\ ${ }^{1}$ Diabetes Endocrine Nutrition Management and Research Centre (DENMARC), India \\ ${ }^{2}$ Consultant Diabetologist and Endocrinologist, India \\ ${ }^{3}$ Mohans Diabetes Specialities Centre, India \\ ${ }^{4}$ Negalur's diabetes \& thyroid specialties center, India \\ ${ }^{5}$ Medical Affairs, Astra Zeneca Pharma India Ltd, India
}

Submission: November 06, 2017; Published: December 07, 2017

*Corresponding author: HB Chandalia, Diabetes Endocrine Nutrition Management and Research Centre (DENMARC), Mumbai, India, Tel: 982-047-0700; Email: denmarc100@gmail.com

\begin{abstract}
There is a rapidly increasing epidemic of type 2 diabetes in India and other Asian countries due to rapid urbanization and lifestyle changes occurring in the country. India faces several challenges in diabetes management, including a rising prevalence in urban and rural areas, lack of disease awareness among the public, limited health care facilities, high cost of treatment, and rising prevalence of diabetic complications. Current antidiabetic agents fail to address disease progression and are often associated with weight gain and risk of hypoglycemia. SGLT2 represents a novel target for the treatment of diabetes. The mechanism of SGLT2 inhibition is independent of circulating insulin levels or insulin sensitivity; therefore, these agents can be combined in type 2 diabetes with all other antidiabetic classes, including exogenous insulin. Dapagliflozin is the first in class SGLT2 inhibitor that is associated with substantial improvements in glycemic control, reduction in weight especially fat mass, modest reduction in blood pressure and low risk of hypoglycemia. Besides this, there are indications that dapagliflozin is capable of improving $\beta$ cell function and reduction in albuminuria. Although the long-term efficacy and safety of SGLT2 inhibitors remain under study, the class represents a novel therapeutic approach in the treatment of type 2 diabetes.
\end{abstract}

Keywords: Dapagliflozin; Metformin; SGLT2 inhibitors; Type 2 diabetes mellitus

\section{Introduction}

\section{Prevalence of T2DM in India}

The prevalence of Type 2 diabetes is rising globally. A recent report by International Diabetes Federation (IDF) on the global scenario shows that the prevalence of diabetes in 2014 was 382 million and estimated to increase to an alarming 592 million by 2035 .Nearly $80 \%$ of the diabetic population lives in the developing countries [1] and greater than $60 \%$ of world diabetes population will be in Asia [2]. Diabetes is fast gaining the status of a potential epidemic in India with more than 62 million diabetic individuals currently diagnosed with the disease [1]. It is predicted that by 2030 diabetes mellitus may afflict up to 79.4 million individuals in India, while China (42.3 million) and United States (30.3 million) will also see significant increases in the disease [1].

\section{Unique challenges in managing T2DM in India}

The etiology of diabetes in India is multifactorial and includes genetic factors along with environmental influences. Some of the major factors which pose unique challenges in managing T2DM in India are presented in Table 1. The prevalence estimates are escalating both in the urban and rural regions of India. Although the prevalence of diabetes is lower in low socioeconomic group versus the high-income groups living in urban areas, the former group has higher prevalence of complications. This is because they tend to neglect the disease due to lack of awareness and also due to economic barriers [3]. Low disease awareness among the population is also one of the major causes for diabetes epidemic [3]. Cost of diabetes care is very high and it increases many-fold in case of complications which require admission to hospital, surgery or insulin treatment. Many patients suffer from vascular complications at the time of diagnosis due to the fact that the person is asymptomatic and has low awareness about the disease. Early diagnosis of diabetes (at pre-diabetes stage) will make early initiation of treatment possible and thus avoid occurrence of vascular complications. Early intervention could also help to preserve the beta cell function [4]. Because of 


\section{Current Research in Diabetes \& Obesity Journal}

progressive nature of diabetes, patients fail to achieve target with multiple anti-diabetic agents. With early diagnosis and proper management, it may be possible to prevent T2DM along with its long term complications. Impaired fasting glucose (IFG) and impaired glucose tolerance (IGT) representation pre-diabetic state which is also highly prevalent in India. Current estimates show that India has nearly 3.0\% of adults with prediabetes [4].

Table 1: Unique Characteristics and challenges in managing T2DM in India.

\begin{tabular}{|c|c|}
\hline Unique Characteristics & Unique Challenges \\
\hline $\begin{array}{c}\text { High ethnic and genetic } \\
\text { susceptibility for the disease }\end{array}$ & $\begin{array}{c}\text { Increased prevalence of Impaired } \\
\text { fasting glucose (IFG) and glucose } \\
\text { tolerance (IGT) }\end{array}$ \\
\hline $\begin{array}{c}\text { Lower threshold limits for the } \\
\text { environmental risk factors. }\end{array}$ & $\begin{array}{c}\text { Obesity associated with rising } \\
\text { living standards }\end{array}$ \\
\hline $\begin{array}{c}\text { Lower body mass index (BMI) } \\
\text { associated with increased } \\
\text { adipose tissue mass Insulin } \\
\text { resistance }\end{array}$ & Delayed diagnosis \\
\hline \multirow{2}{*}{$\begin{array}{c}\text { Lower Insulin secretory capacity } \\
\text { and early beta cell exhaustion. }\end{array}$} & Urban migration \\
\hline \multirow{2}{*}{$\begin{array}{c}\text { Development of the disease at a } \\
\text { young age }\end{array}$} & Lifestyle changes \\
\cline { 2 - 2 } & Lack of awareness \\
\cline { 2 - 2 } & Economic barriers \\
\cline { 2 - 2 } & High cost of disease management \\
\hline
\end{tabular}

\section{Pathophysiological challenges of Indian T2DM patients}

The pathophysiology of T2DM is progressive, characterized by decreased insulin sensitivity, deteriorating beta cell function [5], and decreased incretin function [6]. Decreased insulin function leads to chronic hyperglycemia (during fasting and postprandial periods) and acute glycemic fluctuations. These may be associated with microvascular and macrovascular complications caused by excessive protein glycation and activation of oxidative stress [7-9].

As compared to western countries, India has a higher prevalence of diabetes despite having lower overweight and obesity rates, suggesting that diabetes may occur at a much lower body mass index (BMI) in Indians compared with Europeans [10]. Therefore, lean Indian adults with a lower BMI may be at equal risk as those who are obese [11]. Further, South Asian population has several unique characteristics like onset of diabetes at young age, a relatively lower BMI at the time of diagnosis with accompanying insulin resistance and reduced insulin secretory capacity. This body type is termed as thin-fat phenotype (thin muscle but increased body fat) and is associated with an increased risk of developing diabetes [10]. Indians develop T2DM at a younger age than the western populations and also develop diabetes with minor weight gain [12]. The development of the disease at a young age predisposes the patients to develop chronic long-term complications at a relatively young age with severe morbidity and early mortality in the most productive years of life [12]. Further, Indians are genetically predisposed to the development of coronary artery disease due to dyslipidaemia and low levels of high density lipoproteins; these determinants make Indians more prone to development of the complications of diabetes. Due to high ethnic and genetic susceptibility for the disease, Indians have lower threshold limits for the environmental risk factors and indicate that diabetes must be carefully screened and monitored regardless of patient's age in India $[13,14]$. Under-nutrition during intrauterine development causes permanent changes in the structure and function of the developing systems of the fetus. This increases susceptibility to disease in later life. Asians mothers (especially in rural India) thought to be chronically undernourished because of their low BMI with iron and other nutrient deficiencies. One-third of Indian babies are born with low birth weight $(\mathrm{LBW}<2.5 \mathrm{~kg})$ [15]. It is thus possible that maternal and fetal under nutrition contribute to the diabetes epidemic in the Asian countries [15].

\section{Dietary differences in India and western countries}

Studies have shown that in all parts of India, T2DM patients consume high total and complex carbohydrate ( $\mathrm{CHO}$ ) in their diet when compared with dietary recommendations. An earlier study has shown that $64.1 \pm 8.3 \%$ (95\% CI 63.27 to 64.93 ) of total calories come from $\mathrm{CHO}$ in the T2DM group which has a direct effect on postprandial blood glucose and insulin response [16]. This suggests that $\mathrm{CHO}$ consumption by T2DM patients in India is higher than that recommended by the guidelines [16]. This unique feature in Indian dietary habit makes Indians more prone to T2DM as compared to western countries.

\section{Metformin monotherapy- first line drug}

Metformin stands out not only for its antihyperglycemic properties but also for its effects beyond glycemic control such as improvements in endothelial dysfunction, oxidative stress, insulin resistance, lipid profiles and fat redistribution [17]. Negligible risk of hypoglycaemia when used in monotherapy and few drug interactions of clinical relevance give this drug a high safety profile and most preferred choice as first line therapy.

Current guidelines from ADA/EASD and AACE/ACE recommend early initiation of metformin as a first-line drug for monotherapy and combination therapy for patients with T2DM. This recommendation is based primarily on metformin's glucose-lowering effects, relatively low cost, and generally low level of side effects, including the absence of weight gain [18]. The optimal second-line drug when metformin monotherapy fails is not clear.

\section{Limitations of current OADs}

T2DM is typically managed with rigorous medical therapy and a stepwise approach which includes lifestyle modifications, addition of oral antidiabetic drugs (OADs) and addition of insulin. OADs are normally introduced when lifestyle modifications fail to adequately controlglycemia. They are very useful for managing hyperglycemia, especially in the early 
stages of disease. Insulin and other antihyperglycemic agents like sulfonylureas (SUs), biguanides, thiazolidinediones (TZDs) and incretin based therapies are the drugs routinely used in the treatment of T2DM.However, there are several limitations that prevent antihyperglycemic agents from reaching their potential (Table 2).

Table 2: Limitations of current anti-diabetic agents.

\begin{tabular}{|c|c|c|}
\hline OAD agent & Pros & Cons \\
\hline $\begin{array}{l}\text { Metformin } \\
\text { monotherapy }\end{array}$ & $\begin{array}{c}\text { Lowering HbA1c by } \\
1.5 \% \\
\text { Lower risk of } \\
\text { hypoglycaemia } \\
\text { Weight neutral or } \\
\text { promotes weight loss }\end{array}$ & $\begin{array}{l}\text { Gastro-intestinal } \\
\text { intolerance }\end{array}$ \\
\hline Sulfonylureas (SUs) & $\begin{array}{l}\text { Lowering } \mathrm{HbA1c} \\
\text { effectively in initial } \\
\text { phases }\end{array}$ & $\begin{array}{c}\text { Hypoglycaemia } \\
\text { Weight gain } \\
\text { Cardiovascular } \\
\text { disease } \\
\text { Increased mortality }\end{array}$ \\
\hline $\begin{array}{l}\text { Thiazolidinediones } \\
\text { (TZDs) }\end{array}$ & Glycemic control & $\begin{array}{c}\text { Weight gain } \\
\text { Fluid retention } \\
\text { Congestive cardiac } \\
\text { failure } \\
\text { Increases fracture } \\
\text { risk }\end{array}$ \\
\hline $\begin{array}{l}\text { Incretin-based } \\
\text { therapies }\end{array}$ & $\begin{array}{l}\text { No hypoglycaemia } \\
\text { Weight neutral } \\
\text { Safe in patients with } \\
\text { chronic kidney } \\
\text { disease } \\
\text { Cost effective }\end{array}$ & $\begin{array}{l}\text { Nausea, vomiting, } \\
\text { diarrhoea } \\
\text { Injection site } \\
\text { reactions and nodules } \\
\text { Increased risk for } \\
\text { hospitalization for } \\
\text { heart failure } \\
\text { Pancreatitis } \\
\text { Medullary carcinoma } \\
\text { of the thyroid }\end{array}$ \\
\hline insulin therapy & Glycemic control & $\begin{array}{c}\text { Weight gain } \\
\text { Hypoglycaemia } \\
\text { High Coefficient of } \\
\text { variation of } \\
\text { insulin response }\end{array}$ \\
\hline SGLT2 inhibitors & $\begin{array}{l}\text { Weight loss } \\
\text { Control of BP } \\
\text { Low CV risk }\end{array}$ & $\begin{array}{c}\text { Genital Mycotic } \\
\text { infections } \\
\text { Urinary tract } \\
\text { infections } \\
\text { Negative fluid balance } \\
\text { Elevated LDL } \\
\text { cholesterol } \\
\text { Possible risk for } \\
\text { bladder cancer }\end{array}$ \\
\hline
\end{tabular}

\section{Sulfonylureas (SUs)}

SUs are as effective in lowering HbA1c, but their use is associated with hypoglycaemia and weight gain up to $2 \mathrm{~kg}$ [17].
It has also been found that though they are effective in lowering the blood glucose rapidly in the initial phase of therapy, this effect is not sustained over time. SU therapy was implicated as a potential cause of increased cardiovascular disease mortality in the University Group Diabetes Program study [17].

\section{Thiazolidinediones (TZDs)}

TZDs, well known as insulin sensitizers, appear to have a more durable effect on glycemic control, particularly in comparison with SUs [19]. However, TZDs lead to weight gain, fluid retention, peripheral oedema, and a two-fold increased risk for congestive cardiac failure, potential for increased fracture risk [19].

\section{Incretin based therapies}

Glucagon-like peptide-1 receptor agonists and dipeptidyl peptidase-4 inhibitors offer analtered way of reducing hyperglycaemia by targeting the incretin system. GLP-1based therapies have a beneficial effect on weight, because of their inhibitory effect on appetite via the gut-brain axis [20]. However, use of GLP-1 RA is associated with dose-dependent gastrointestinal side effects including nausea, vomiting and diarrhoea, and also two potential safety issues are pancreatitis and medullary carcinoma of the thyroid [21]. DPP 4 inhibitors are less potent to reduce hyperglycaemia compared to GLP 1 RA and besides that they are weight neutral [21].

\section{Insulin therapy}

Insulin therapy is often accompanied by hypoglycemia and weight gain which have been identified by patients and health care providers as common concerns prior to insulin initiation. These are key factors responsible for patients reluctance to insulin intensification [22]. Interestingly, the weight gain associated with insulin therapy is mainly seen in patients who had experienced significant weight loss prior to institution of insulin therapy [23]. Further, traditional vial and syringe method of insulin administration is associated with needle stick injury, social stigma, lack of convenience, difficulty with accurate dosing and therefore decreased adherence to the prescribed insulin regimen. New insulin analogs are effective in reducing HbA1c levels with a lower risk of overall and nocturnal hypoglycemia compared with conventional insulins [24]. They have also been shown to induce less weight gain than either NPH or insulin glargine [24].

Of immense therapeutic importance, intra subject coefficient of variation of insulin response has been shown to be $20-40 \%$, $20 \%$ for human regular and rapid acting analogues and $40 \%$ for Neutral Protamine Hagedorn (NPH) and glargine insulin. All the above pharmacological drugs focus on reducing hyperglycemia and improving insulin sensitivity. These drugs target the primary defects associated with T2DM. However, despite the wide choice of treatment options available, glycemic control declines over time and eventually combination of other antihyperglycemic agents is required [25]. 


\section{Sodium-glucose co-transporter 2 (SGLT2) inhibitors: novel therapy independent of Insulin}

SGLT2 inhibitors are a new class of oral antidiabetic drugs, which reduce hyperglycemia by increasing urinary glucose excretion independent of insulin action [26]. SGLT2, located in the renal proximal tubule, reabsorbs $90 \%$ of the filtered glucose [27] and its inhibition represents a new form of pharmacotherapy for the treatment of type 2 diabetes. The mechanism of action of SGLT2 inhibitors is unique and does not depend upon beta-cell function or tissue insulin sensitivity [26]. Through SGLT2 inhibition, reabsorption of tubular glucose is reduced and urinary glucose excretion increased [27] SGLT2 inhibitor induced glucose excretion is proportional to the amount of glucose filtered by the kidneys, which is a function of the glomerular filtration rate (GFR) and plasma glucose concentration [28]. Increased plasma glucose concentration (as observed in DM) leads to increased glucose filtration (dependent on the GFR) and may allow greater excretion of glucose with SGLT2 inhibition. The effect of SGLT2 inhibitors diminishes as patients plasma glucose concentrations decrease, the intrinsic risk of hypoglycemia with this drug class is low [28].

\section{Dapagliflozin}

Dapagliflozin, a potent and selective SGLT2 inhibitor, has been shown to improve glycemic control in patients with type 2 diabetes when used as monotherapy [29-31] or in combination with metformin [32,33], sulfonylureas [34-36], thiazolidinedione [37], DPP4 inhibitors [38], or insulin [39].

\section{Glycemic efficacy}

Multiple trials have examined the efficacy of dapagliflozin versus placebo in lowering the HbA1c in drug-naive T2DM individuals. In a 24-week multicenter study [31], decrease in dapagliflozin treated subjects HbA1c was $0.5-0.6 \%$ (from a baseline HbA1c of 7.8-8.0\%) and FPG decrease by $\sim 25 \mathrm{mg} / \mathrm{dl}$ (from a baseline FPG of $160 \mathrm{mg} / \mathrm{dl}$ ). In a subgroup of subjects with baseline HbA1c of 10.1-12.0\%, dapagliflozin (5 and 10mg/ day) reduced the $\mathrm{HbA} 1 \mathrm{c}$ by 2.88 and $2.66 \%$, respectively. In another 24-week study [29,30], Dapagliflozin lowered the HbA1c by $0.7-0.8 \%$ from a baseline HbA1c of $7.8-8.1 \%$. The efficacy of dapagliflozin in lowering the plasma glucose concentration as add-on therapy has been examined in poorly controlled T2DM treated with metformin, sulfonylureas and pioglitazone. Dapagliflozin effectively reduced the HbA1c in poorly controlled diabetic individuals independent of the background therapy. In a 24-week study [32], metformin-treated individuals with HbA1c 7-10\% were randomized to receive different doses of dapagliflozin or placebo. The placebo-subtracted reduction in $\mathrm{HbA1c}$ at 24 weeks was -0.37 to $-0.54 \%$. Dapagliflozin also produced a dose-dependent decrease in FPG. 71\% of subjects in this study participated in a 102-week extension study and the decrease in HbA1c was maintained at 102 weeks [33].

As add-on therapy, dapagliflozin has been shown to have similar potency to sulfonylureas in lowering the HbA1c in poorly controlled metformin-treated diabetic subjects. In a 52-week head-to-head study [34], meformin-treated subjects (HbA1c $>6.5 \%$ ) were randomized to receive dapagliflozin or glipizide. After an 8-week lead in period, dapagliflozin and glipizide were up-titrated over 18 weeks to 10 and $20 \mathrm{mg}$, respectively. The decrease in HbA1c at 52 weeks was identical in both groups (0.52\%) [34], and the decrease in HbA1c in dapagliflozin-treated subjects was maintained at 102 weeks [35]. In a 24-week study [36], sulfonylurea treated subjects with poor glycemic control (HbA1c 7-10\%) were randomized to receive different doses of dapagliflozin or placebo. The placebo-subtracted decrease in $\mathrm{HbA} 1 \mathrm{c}$ was -0.44 to $-0.68 \%$, respectively. Dapagliflozin (5 and $10 \mathrm{mg}$ ) has also been examined in a 24-week study [37] in poorly controlled (mean HbA1c 8.4\%), pioglitazone-treated T2DM subjects. The placebo-subtracted decrease in HbA1c was -0.40 and $-0.55 \%$, respectively, and the decrease in $\mathrm{HbA} 1 \mathrm{c}$ was maintained at 48 weeks. Dapagliflozin equally reduced the fasting and the postprandial plasma glucose concentration by $25 \mathrm{mg} / \mathrm{dl}$.

In a larger study ( $\mathrm{n}=800)$, [39] the addition of dapagliflozin $(2.5,5$ and $10 \mathrm{mg} /$ day) to insulin-treated T2DM individuals (receiving $\sim 70-80$ units/day for a mean of $\sim 6$ years) caused a dose-dependent decrease in HbA1c $(-0.40,-0.49$ and $-0.57 \%$, respectively) compared with placebo over 24 weeks and the decrease in HbA1c was maintained at 48 weeks [39].

Other factors which play important role in the pathophysiology of T2DM were also improved by dapagliflozin alone or in combination with other diabetic drugs. Hypertension and albuminuria are risk factors for cardiovascular (CV) and renal disease in patients with T2DM [40]. Control of glycemia, blood pressure (BP) and albuminuria are critical for reducing CV and renal risk. Dapagliflozin reduces $\mathrm{HbA1c}$ and BP in patients with T2DM and also reduces urinaryalbumin:creatinine ratio in T2DM patients with hypertension using renninangiotensin system blockade without increasing any renal AEs [40]. Further, dapagliflozin improved glycemia in T2D patients with CVD, and improved insulin sensitivity in patients with T2D for up to 52 weeks. [41] Dapagliflozin alone and in combination with saxagliptin was shown to improve ßcell function and increased insulin clearance [42].

\section{Non-glycemic benefits of dapagliflozin}

In addition to the beneficial effects related to improved glycemic control, dapagliflozin exerts additional non-glycemic benefits in T2DM patients that make the drug desirable as monotherapy and as combination therapy.

\section{Weight loss}

The urinary loss of $60-80 \mathrm{~g}$ of glucose per day equates to a negative energy balance of $240-320 \mathrm{cal} /$ day or an equivalent body weight of 2-3pounds/month if this caloric deficit is not offset by an increase in caloric intake. Consistent with this, weight loss was observed in diabetic subjects treated with 


\section{Current Research in Diabetes \& Obesity Journal}

dapagliflozin at all doses and at all stages of the disease [43]. Reduction in body weight was $2.26 \mathrm{~kg}$ to $5.43 \mathrm{~kg}$ as monotherapy [44], second add on therapy or add on to Insulin [44]. The weight loss primarily was due to a decrease in fat mass which is $2 / 3 \mathrm{rd}$ [44] while lean tissue mass reduction was $1 / 3 \mathrm{rd}$ as measured by dual-energy X-ray absorptiometry (DXA). Reduction in waist circumference was $2.5 \mathrm{~cm}$ [44].

\section{Blood pressure}

A consistent finding in all dapagliflozin studies has been a reduction in systolic/diastolic blood pressure of 4-5/2-3mmHg respectively [45]. This has been attributed to the diuretic effect that occurs during the initial days of dapagliflozin treatment [46]. Since uric acid and sodium reabsorption in the proximal tubule are coupled, decrease in serum uric acid concentration consistently has been observed in diabetic patients treated with dapagliflozin [47].

\section{Safety profile of dapagliflozin}

A major safety concern for anti-diabetic agents is the potential for patients to develop hypoglycaemia. Indeed, thus far, clinical trials have revealed virtually no instances of major hypoglycemic events, despite some increased risk of mild or moderate hypoglycemic events, which mostly occurred when they are superimposed with the background SU and Insulin therapy [34,39]. Clinical trials have consistently shown the early SGLT2 inhibitor dapagliflozin to be a safe agent for diabetic patients. Following an initial safety trial in healthy subjects showing that dapagliflozin was safe and well tolerated and did not induce hypoglycemia or produce any other adverse events [47], its safety was examined in type 2 diabetic patients, confirming that multiple oral doses of dapagliflozin rarely caused major hypoglycemia or other adverse events [29].

An increased incidence of mycotic vulvo-vaginal infections in women and mycotic balanitis in males has been observed. Rates of balanitis in men are several-fold less than rates of vulvovaginitis in women, and both infections are easily resolved by standard therapies [29]. SGLT2 inhibitors also possess a diuretic effect, hence symptoms related to volume depletion may occur [48]. Consequently, these agents should be used cautiously in elderly, any patient already on a diuretic, and patient with tenuous intravascular volume status.

Studies with dapagliflozin have demonstrated that treatment with an SGLT2 inhibitor has no deleterious effect on renal function [49]. Moreover, because the majority of drug's clearance is by the liver, no dose adjustment is necessary in patients with renal impairment [49]. Because of its mechanism of action, the efficacy of dapagliflozin to reduce plasma glucose concentrations is highly dependent on the level of renal function. As the GFR declines, there is a decrease in the filtered glucose load and a progressive decrease in the glucose lowering ability of the drug. Thus dapagliflozin is not recommended if eGFR is $<45 \mathrm{mi} / \mathrm{min} / 1.73 \mathrm{~m}^{2}$ [48].
It is possible that SGLT2 inhibitor therapy may prevent diabetic nephropathy. Enhanced sodium-glucose reabsorption in the proximal tubule has been shown to play an important role in the development of diabetic nephropathy [49]. SGLT2 inhibitors may prevent diabetic nephropathy not only by reducing the plasma glucose concentration but also by increasing sodium delivery to the distal nephron, thereby inhibiting the glomerulotubular feedback reflex [49]. Type 2 diabetes is a major risk factor for cardiovascular (CV) disease, and the presence of both Type 2 diabetes and cardiovascular disease increases the risk of death [50]. There is concern that intensive glucose lowering or the use of specific glucose-lowering drugs may be associated with adverse cardiovascular outcomes. Therefore, it is necessary to establish the cardiovascular safety benefits of glucose-lowering agents [51]. Since the mode of action of SGLT2 inhibitors is independent of insulin secretion; these agents are associated with a low risk of hypoglycemia, which has been linked to increased CV events. In addition, the drug has been demonstrated to ameliorate a variety of $\mathrm{CV}$ risk factors and potential pathways as described in Figure 1 [52]. Dapagliflozin has an acceptable CV profile. Meta-analyses have been performed analyzing the cardiovascular safety of dapagliflozin [53].

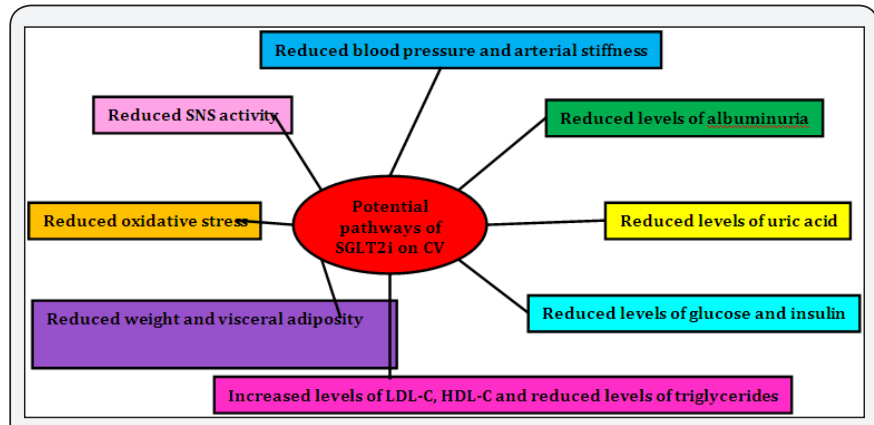

Figure 1: Potential mechanisms of $\mathrm{CV}$ risk reduction with SGLT 2 Inhibitors [51].

Meta-analysis did not show an increased CV risk for dapagliflozin-treated patients, with no evidence for an increased risk of major CV events and with hazard ratios $<1$ consistently across various composite $\mathrm{CV}$ endpoints and across different subgroups [53]. Also, EMPA-REG study with Empagliflozin, another SGLT2, showed that T2DM patients with high risk for cardiovascular events who received empagliflozin, as compared with placebo, had a lower rate of the primary composite cardiovascular outcome and of death from any cause when the study drug was added to standard care [54]. In CVD REAL, A large multinational study, treatment with SGLT-2i versus oGLDs was associated with a lower risk of HHF and death, suggesting that the benefits seen with empagliflozin in a randomized trial may be a class effect applicable to a broad population of T2D patients in real-world practice [55]. In CVD REAL Nordic study a total of 40,908 patients with T2D were identified as new users of dapagliflozin ( $n=10227)$ ora DPP 4 inhibitor $(n=30681)$. Dapagliflozin was associated with a lower risk of MACE, HHF and all-cause mortality compared with DPP-4 inhibitors: HRs 0.79 


\section{Current Research in Diabetes \& Obesity Journal}

(95\%confi-dence interval [CI] 0.67-0.94), 0.62(95\% CI 0.50 0.77), and 0.59(95\% CI 0.49-0.72), respectively [56].

Recently, the U.S. Food and Drug Administration (FDA) issued a Drug Safety Communication that warns of an increased risk of diabetic ketoacidosis (DKA) with surprisingly mild to moderate glucose elevations (euglycemic DKA [euDKA]) associated with the use of all the approved sodium-glucose cotransporter 2 (SGLT2) inhibitors [57]. In the randomized controlled T2D study program, more than 18,000 patients exposed to dapagliflozin and the frequency of reported events suggestive of DKA (blinded and unblinded events) was less than $0.1 \%$ [56]. Similarly in DECLARE study 17,150 patients randomized todapagliflozin or placebo, the total number of reported blinded events of potential DKAs is less than $0.1 \%$ [58]. In a retrospective analysis of randomized phase 2 and 3 empagliflozin trials (13,000 T2D participants), there were eight events consistent with DKA with no imbalance observed between patients treated with empagliflozin $10 \mathrm{mg}$ (two events), empagliflozin $25 \mathrm{mg}$ (one event), and placebo (five events) [59]. The canagliflozin (another SGLT2 inhibitor) data reported by Erondu et al. [60] appeared to have a greater incidence of DKA, but 6 out of the 12 cases had evidence of latent autoimmune diabetes in adults or T1D or tested positive for GAD65 antibodies. Thus the evidence so far suggests that the risk of euDKA (and not simple ketosis) in T2DM related to the use of SGLT2 inhibitors will probably turn out to be very low with an acceptable frequency. Still, physicians and patients need to be made aware that such risk may be increased in long-standing T2DM patients with marked beta-cell insufficiency or in latent autoimmune diabetes. This potential complication related to SGLT2 inhibition is predictable, detectable, and preventable so that the balance of benefits and risks favors the use of SGLT2 inhibitors in the T2DM population [58].

\section{SGLT 2 inhibitors added on to metformin}

Numerous preclinical and clinical studies indicate that SGLT2 inhibitors are efficacious but still they may not be the first choice for T2DM therapy. Currently, the standard first line therapy is metformin, due to its low cost and favourable safety profile. SGLT2 inhibitors could quickly become a second-line therapy, and may possibly replace metformin as the first-line therapy in the future [61]. SGLT2 inhibitors may be a particularly good choice for T2DM patients who do not achieve adequate glycaemic control with metformin or other anti-diabetic drugs. In two clinical studies, dapagliflozin as an add-on to metformin decreased HbA1c levels significantly without any serious adverse effects [32].

\section{International guidelines for T2DM}

ADA guidelines recommend weight loss for all overweight or obese individuals who have /are at risk for diabetes. Weight reduction is especially important in Asians who have lower cut-offs for overweight and obesity and hence are highly predisposed to development of diabetes and worsening of diabetes [59]. Shantha et al. [60], in 2012 demonstrated that intentional weight loss of $10 \%$ in obese individuals with T2DM could potentially decrease percentage $\mathrm{HbA} 1 \mathrm{c}$ by $0.81 \%$. WHO recommends lowered cut-off points for overweight/obesity for Asians in the Asia Pacific region (overweight: $\mathrm{BMI}=23 \mathrm{~kg} / \mathrm{m}^{2}$ in comparison with $25 \mathrm{~kg} / \mathrm{m}^{2}$ for western populations) [10].

The major change in treatment options since the publication of the 2012 position statement has been the availability of a new class of glucose-lowering drugs, the sodium-glucose cotransporter 2 (SGLT2) inhibitors. These agents reduce HbA1c by $0.5-1.0 \%(5.5-11 \mathrm{mmol} / \mathrm{mol})$ versus placebo [61]. When compared with most standard anti-diabetic agents in headto-head trials, they appear to be roughly similarly efficacious with regard to initial HbA1c lowering [62]. Additional potential advantages include modest weight loss and consistent lowering of systolic and diastolic blood pressure along with reductions in plasma uric acid levels and albuminuria [63]. Current treatment guidelines approved SGLT2 inhibitors as monotherapy, they are mainly used in combination with metformin and/or other agents. Given their demonstrated efficacy and clinical experience to date, they are reasonable options as second-line or third-line agents [61].

All major organizations (American Diabetes Association (ADA)/European Association for the Study of Diabetes (EASD)/ American Association of Clinical Endocrinologists (AACE)) recommend metformin as first-line therapy in individuals with new-onset diabetes and also recommend as a combination therapy with other anti-diabetic agent in case of disease progression. Dapagliflozin is an effective novel strategy to reduce the plasma glucose concentration in type 2 diabetic subjects. The drug's unique mechanism of action, which is independent of insulin sensitivity and beta cell function, allows the use of dapagliflozin in combination with all other antidiabetic agents and at all stages of the disease. However, because metformin does not improve beta cell function, metformin-treated individuals experience a progressive increase in $\mathrm{HbA1c}$ after the first year of therapy. Dapagliflozin can provide an effective therapeutic option in metformin-failing diabetic individuals. An increase in the plasma glucagon-like peptide-1 (GLP-1) concentration has been observed in some clinical studies following initiation of dapagliflozin therapy. This observation makes the double combination of dapagliflozin plus a dipeptidyl peptidase IV (DPP-IV) inhibitor an attractive therapeutic option in metformin-failing individuals. In newly diagnosed T2DM individuals with a very high HbA1c (e.g., >9.0\%), metformin alone will not lower the HbA1c to the treatment goal $(<7.0 \%)$. Dapagliflozin plus metformin have an additive effect to lower the HbA1c. Dapagliflozin monotherapy produces a profound decrease in $\mathrm{HbA1}$ c in patients with a high initial HbA1c (>9.0\%). The combination of dapagliflozin plus metformin is an attractive therapeutic option in newly diagnosed diabetic individuals with a high initial HbA1c. Dapagliflozin can provide an effective therapeutic option in metformin-failing diabetic individuals. Metformin cannot be started in about $10-20 \%$ of subjects with new-onset diabetes due to either gastrointestinal (GI) side effects 


\section{Current Research in Diabetes \& Obesity Journal}

or due to renal failure. Thus, dapagliflozin, as monotherapy or in combination with a DPP-IV inhibitor, can provide an effective initial therapy in metformin-intolerant individuals. Because dapagliflozin is effective in lowering the HbA1c at all stages of diabetes, it can be added in subjects who fail on multiple oral agent therapy or in insulin-treated individuals who do not reach the target glycemic control. Progressive beta-cell failure is the principle factor responsible for the progression of T2DM. Thus, preservation of $\beta$-cell function can be expected to produce a durable reduction in HbA1c. More data will be required before making definitive conclusions about the durability of dapagliflozin. To the extent that glucotoxicity contributes to the decline in beta-cell function in subjects with impaired glucose tolerance (IGT) or impaired fasting glucose (IFG), these drugs also may prove useful in the treatment of 'prediabetes'. Lastly, unlike most currently available antidiabetic agents, SGLT 2 inhibitors promote weight loss and reduces blood pressure which would be expected to have potential cardiovascular benefit $[64,65]$.

\section{Conclusion}

The pathogenesis of type 2 diabetes involves numerous defects and no single anti-diabetic agent can correct all these metabolic disturbances. An effective anti-diabetic therapy will require multiple drugs used in combination. Based on expert commentsinhibition of SGLT2 represents a highly promising therapeutic approach for T2DM treatment. With a unique mechanism of action-increased urinary glucose excretionthe SGLT2 inhibitors can be used as monotherapy as well as in combination with currently available anti-diabetic agents. Their distinct, targeted mechanism of action makes SGLT2 inhibitors good candidates for combination therapies with other anti-diabetic agents as well as insulin. Moreover, due to their high potential to control hyperglycemia, effect on visceral fat and improvement in insulin sensitivity, SGLT2 inhibitors are expected to have protective effects against micro and macrovascular complications. With these properties, the SGLT2 inhibitors have potential for use throughout the continuum of diabetes treatment in Indian populationas Indian patient's needs are unique due to environmental, social and genetic facts. Considering International glycemic control guidelines, mechanism of action, substantial improvements with respect to glycemic and extragycemic parameters and safety profile associated with Dapagliflozin, it could be excellent choice for managing T2DM after metformin in Indian patients.

\section{Acknowledgement}

The authors acknowledge Astra Zeneca Pharma India Ltd and Tech Observer for Medical writing and editing support.

\section{Conflict of Interest}

H B Chandalia, Suresh Damodharan, NG Sastry and Vijay Negalur are on the speaker bureau of Astra Zenecaand Shital Sardais Regional Medical Advisor at Astra Zeneca.

\section{References}

1. (2013) International Diabetes Federation IDF Diabetes Atlas. ( $6^{\text {th }}$ edn $)$, The global Burden.

2. Ramachandran A, Snehalatha C, Shetty AS, Nanditha A (2012) Trends in prevalence of diabetes in Asian countries. World J Diabetes 3(6): 110-117.

3. Murugesan N, Snehalatha C, Shobhana R, Roglic G, Ramachandran A, et al. (2007) Awareness about diabetes and its complications in the general and diabetic population in a city in southern India. Diabetes Res Clin Pract 77(3): 433-437.

4. Anjana RM, Pradeepa R, Deepa M, Datta M, Sudha V, et al. (2011) Prevalence of diabetes and prediabetes (impaired fasting glucose and/or impaired glucose tolerance) in urban and rural India: phase 1 results of the Indian Council of Medical Research India Diabetes (ICMR-INDIAB) study. Diabetologia 54(12): 3022-3027.

5. Rahilly SP, Nugent Z, Rudenski AS, Hosker JP, Burnett MA, et al. (1986) $\beta$-cell dysfunction, rather than insulin insensitvity, is the primary defect in familial type 2 diabetes. Lancet 2(8503): 360-364.

6. Knop FK, Vilsbøll T, Højberg PV, Larsen S, Madsbad S, et al. (2007) Reduced incretin effect in type 2 diabetes: cause or consequence of the diabetic state? Diabetes 56(8): 1951-1959.

7. Horie K, Miyata T, Maeda K, Miyata S, Sugiyama S, et al. (1997) Immuno histochemical colocalization of glycoxidation products and lipid peroxidation products in diabetic renal glomerular lesions. Implication for glycoxidative stress in the pathogenesis of diabetic nephropathy. J Clin Invest 100(12): 2995-2999.

8. Monnier L, Colette C (2008) Glycemic variability: should we and can we prevent it? Diabetes Care 31(2): S150-S154.

9. Degenhardt TP, Thorpe SR, Baynes JW (1998) Chemical modification of proteins by methylglyoxal. Cell Mol Biol (Noisyle- grand) 44(7): 11391145.

10. Banerji MA, Faridi N, Atluri R, Chaiken RL, Lebovitz HE, et al. (1999) Body composition, visceral fat, leptin and insulin resistance in Asian Indian men. J Clin Endocrinol Metab 84(1): 137-144.

11. Chandalia M, Abate N, Garg A, Gundersen J, Grundy SM, et al. (1999) Relationship between generalized and upper body obesity to insulin resistance in Asian Indian men. J Clin Endocrinol Metab 84(7): 23292335.

12. Ramchandran A, Viswanathan M, Mohan V (1993) Epidemiology of NIDDM in Indians. J Assoc Physicians India 41: 1-3.

13. Ramachandran A, Mary S, Yamuna A, Murugesan N, Snehalatha C, et al. (2008) High prevalence of diabetes and cardiovascular risk factors associated with urbanization in India. Diabetes Care 31(5): 893-898.

14. Misra A, Khurana L (2011) Obesity-related non-communicable diseases: South Asians vs White Caucasians. Int J Obes (Lond) 35(2): 167-187.

15. Yajnik CS, Fall CH, Coyaji KJ, Hirve SS, Rao S, et al. (2003) Neonatal anthropometry: the thin-fat Indian baby. The Pune Maternal Nutrition Study. Int J Obes Relat Metab Disord 27(2): 173-180.

16. Misr A, Sharma R, Gulati S, Joshi SR, Sharma V, et al. (2011) Consensus dietary guidelines for healthy living and prevention of obesity, the metabolic syndrome, diabetes, and related disorders in Asian Indians. Diabetes Technol Ther 13(6): 683-694.

17. Meinert CL, Knatterud GL, Prout TE, Klimt CR (1970) A study of the effects of hypoglycemic agents on vascular complications in patients with adult-onset diabetes. II. Mortality results. Diabetes 19: 789-830.

18. (2011) Summary of revisions to the 2011 clinical practice recommendations. Diabetes Care 34(1): S3. 


\section{Current Research in Diabetes \& Obesity Journal}

19. Jarvinen H (2004) Thiazolidinediones. N Engl J Med 351: 1106-1118.

20. Edholm T, Degerblad M, Grybäck P, Hilsted L, Holst JJ, et al. (2010) Differential incretin effects of GIP and GLP-1 on gastric emptying, appetite, and insulin-glucose homeostasis. Neurogastroenterol Motil 22(11): 1191-1200.

21. Drucker DJ, Sherman SI, Gorelick FS, Bergenstal RM, Sherwin RS, et al (2010) Incretin-based therapies for the treatment of type 2 diabetes: evaluation of the risks and benefits. Diabetes Care 33(2): 428-433.

22. Russell JD, Khan R (2007) Insulin-associated weight gain in diabetes causes, effects and coping strategies. Diabetes Obes Metab 9(6): 799812.

23. Chandalia HB, Lamba PS, Chandalia SH, Singh DK, Modi Sonal V, et al. (2005) Weight gain in Type 2 diabetics with different treatment modalities. Metab Syndr Relat Disord 3(2): 157-163.

24. Hermansen K, Davies M, Derezinski T, Martinez RG, Clauson P, et al. (2006) A 26-week, randomized, parallel, treat-to-target trial comparing insulin detemir with NPH insulin as add-on therapy to ora glucose-lowering drugs in insulin-naive people with type 2 diabetes. Diabetes Care 29(6): 1269-1274.

25. Bailey CJ (2003) Antidiabetic drugs. Br J Cardiol 10: 128-136.

26. Raskin P (2013) Sodium-glucose cotransporter inhibition: therapeutic potential for the treatment of type 2 diabetes mellitus. Diabetes Metab Res Rev 29(5): 347-356.

27. Komoroski B, Vachharajani N, Boulton D, Kornhauser D, Geraldes M et al. (2009) Dapagliflozin, a novel SGLT2 inhibitor, induces dosedependent glucosuria in healthy subjects. Clin Pharmacol Ther 85(5): 520-526.

28. List JF, Whaley JM (2011) Glucose dynamics and mechanistic implications of SGLT2 inhibitors in animals and humans. Kidney Int Suppl 120: S20-S27.

29. (2011) FDA Briefing Document NDA 202293. Dapagliflozin tablets 5 and 10mg. In: Products Do Mae (Ed.), Silver Spring: Food and Drug Administration.

30. Ferrannini E, Ramos SJ, Salsali A, Tang W, List JF, et al. (2010) Dapagliflozin monotherapy in type 2 diabetic patients with inadequate glycemic control by diet and exercise: a randomized, double-blind placebo-controlled, phase 3 trial. Diabetes Care 33(10): 2217-2224.

31. Bailey CJ, Iqbal N, T'joen C, List JF (2012) Dapagliflozin monotherapy in drug-naive patients with diabetes: a randomized-controlled trial of low-dose range. Diabetes Obes Metab 14(10): 951-959.

32. Bailey CJ, Gross JL, Pieters A, Bastien A, List JF (2010) Effect of dapagliflozin in patients with type 2 diabetes who have inadequate glycaemic control with metformin: a randomised, double-blind placebo-controlled trial. Lancet 375(9733): 2223-2233.

33. Baily CJ, Yadav M, Gross JL, Iqbal N, Mansfield TA, et al. (2011) Sustained efficacy of dapagliflozin when added to metformin in type 2 diabetes inadequately controlled by metformin monotherapy. Diabetologia 54(S1): S67.

34. Nauck MA, Del Prato S, Meier JJ, García SD, Rohwedder K, et al. (2011) Dapagliflozin versus glipizide as add-on therapy in patients with type 2 diabetes who have inadequate glycemic control with metformin: a randomized, 52-week, double-blind, active-controlled noninferiority trial. Diabetes Care 34(9): 2015-2022.

35. Del Prato S, Nauck M, Durán Garcia S, Maffei L, Rohwedder K, et al. (2015) Long term efficacy and safety of add-on dapagliflozin vs addon glipizide in patients with type 2 diabetes mellitus inadequately controlled with metformin: 208 weeks results Diabetes Obes Metab 17(6): 581-590.

36. Strojek K, Yoon KH, Hruba V, Elze M, Langkilde AM, et al. (2011) Effect of dapagliflozin in patients with type 2 diabetes who have inadequate glycaemic control with glimepiride: a randomized, 24-week, doubleblind, placebo-controlled trial. Diabetes Obes Metab 13(10): 928-938.

37. Rosenstock J, Vico M, Wei L, Salsali A, List JF (2012) Effects of dapagliflozin, an SGLT2 inhibitor, on $\operatorname{HbA}(1 \mathrm{c})$, body weight, and hypoglycemia risk in patients with type 2 diabetes inadequately controlled on pioglitazone monotherapy. Diabetes Care 35(7): 14731478.

38. Jabbour SA, Hardy E, Sugg J, Parikh S (2014) Dapagliflozin is effective as add on therapy to Sitagliptin with or without Metformin: 24 week, multicentre, randomised, double blind, placebo Controlled study. Diabetes care 37(3): 740-750.

39. Wilding JP, Woo V, Soler NG, Pahor A, Sugg J, et al. (2012) Long-term efficacy of dapagliflozin in patients with type 2 diabetes mellitus receiving high doses of insulin: a randomized trial. Ann Intern Med 156(6): 405-415

40. Lambers Heerspink HJ, Johnsson E, Nilsson IG, Sjöström C (2015) Erratum to: Abstracts of the $51^{\text {st }}$ Annual Meeting of the EASD Stockholm 2015. 'Dapagliflozin reduces albuminuria on top of reninangiotensin system blockade in hypertensive patients with diabetes'. Diabetologia 58(12): 2901

41. Katz AH (2015) Dapagliflozin and insulin resistance in patients with type 2 diabetes Clinical Therapeutics/New Technology.

42. Elkholm EHL, Iqbal N , Carlsson B, Chen H, Hirshberg B (2015) Combined treatment with Saxagliptin+Dapagliflozin improves $\beta$ cell function and reduces insulin levels by increased insulin clearance. Clinical Therapeutics /New Technology.

43. Zhang L, Feng Y, List J, Kasichayanula S, Pfister M (2010) Dapagliflozin treatment in patients with different stages of type 2 diabetes mellitus: effects on glycaemic control and body weight. Diabetes Obes Metab 12(6): 510-516.

44. Bolinder J, Ljunggren Ö, Kullberg J, Johansson L, Wilding J, et al. (2012) Effects of dapagliflozin on body weight, total fat mass, and regional adipose tissue distribution in patients with type 2 diabetes mellitus with inadequate glycemic control on metformin. J Clin Endocrinol Metab 97(3): 1020-1031.

45. Vallon V, Richter K, Blantz RC, Thomson S, Osswald H (1999) Glomerular hyperfiltration in experimental diabetes mellitus: potential role of tubular reabsorption. J Am Soc Nephrol 10(12): 2569-2576.

46. Thomson SC, V Vallon, RC Blantz (2004) Kidney function in early diabetes: the tubular hypothesis of glomerular filtration. Am J Physio Renal Physiol 286(1): F8-F15.

47. Vasilakou D, Karagiannis T, Athanasiadou E, Mainou M, Liakos A, et al. (2013) Sodium-glucose cotransporter 2 inhibitors for type 2 diabetes: a systematic review and meta-analysis. Ann Intern Med 159(4): 262 274.

48. Weir MR, Kline I, Xie J, Edwards R, Usiskin K (2014) Effect of canagliflozin on serum electrolytes in patients with type 2 diabetes in relation to estimated glomerular filtration rate (eGFR). Curr Med Res Opin 30(9): 1759-1768

49. Kasichayanula S, Liu X, Pe Benito M, Yao M, Pfister M, et al. (2013) The influence of kidney function on dapagliflozin exposure, metabolism and pharmacodynamics in healthy subjects and in patients with type 2 diabetes mellitus. Br J Clin Pharmacol 76(3): 432-444.

50. Sarwar N, Gao P, Seshasai SR, Gobin R, Kaptoge S, et al. (2010) Diabetes mellitus, fasting blood glucose concentration, and risk of vascular disease: a collaborative meta-analysis of 102 prospective studies. Lancet 375(9733): 2215-2222.

51. Department of Health and Human Services, Food and Drug Administration (2008) Guidance for industry: diabetes mellitusevaluating cardiovascular risk in new antidiabetic therapies to treat type 2 diabetes. 


\section{Current Research in Diabetes \& Obesity Journal}

52. Inzucchi SE, Zinman B, Wanner C, Ferrari R, Fitchett D, et al. (2015) SGLT-2 inhibitors and cardiovascular risk: proposed pathways and review of ongoing outcome trials. Diab Vasc Dis Res 12(2): 90-100.

53. FDA (2013) Endocrinologic and Metabolic Drugs Advisory Committee Meeting. Dapagliflozin.

54. Zinman B, Wanner C, Lachin JM, Fitchett D, Bluhmki E, et al. (2015) Empagliflozin, Cardiovascular Outcomes, and Mortality in Type 2 Diabetes. N Engl J Med 373: 2117-2128.

55. Kosiborod M, Cavender MA, Fu AZ, Wilding JP, Khunti K, et al. (2017) Lower risk of heart failure and death in patients Initiated on SGLT-2 inhibitors versus other glucose-lowering drugs: The CVD-REAL Study. Circulation.

56. Persson F, Nyström T, Jørgensen ME, Carstensen B, Gulseth HL, et al (2017) Dapagliflozin is associated with lower risk of cardiovascular events and all-cause mortality in people with type2 diabetes (CVDREALNordic) when compared with dipeptidylpeptidase-4 inhibitor therapy: A multinational observational study. Diabetes Obes Metab.

57. U.S. Food and Drug Administration. Drug Safety Communication (2015) FDA warns that SGLT2 inhibitors for diabetes may result in a serious condition of too much acid in the blood.

58. Rosenstock J, Ferrannini E (2015) Euglycemic diabetic ketoacidosis: a predictable, detectable, and preventable safety concern with SGLT2 inhibitors. Diabetes Care 38(9): 1638-1642.
59. European Medicines Agency (2015) Review of diabetes medicines called SGLT2 inhibitors started: risk of diabetic ketoacidosis to be examined.

60. Erondu N, Desai M, Ways K, Meininger G (2015) Diabetic ketoacidosis and related events in the canagliflozin type 2 diabetes clinical program. Diabetes Care 38(9): 1680-1686.

61. (2017) Standards of Medical Care in Diabetes Diabetes Care 40: S1S134.

62. Shantha GP, Kumar AA, Kahan S, Cheskin LJ (2012) Association between glycosylated hemoglobin and intentional weight loss in overweight and obese patients with type 2 diabetes mellitus: a retrospective cohort study. Diabetes Educ 38(3): 417-426.

63. Musso G, Gambino R, Cassader M, Pagano G (2012) A novel approach to control hyperglycemia in type 2 diabetes: sodium glucose co-transport (SGLT) inhibitors: systematic review and meta-analysis of randomized trials. Ann Med 44(4): 375-393.

64. Goring S, Hawkins N, Wygant G, Roudaut M, Townsend R, et al. (2014) Dapagliflozin compared with other oral anti-diabetes treatments when added to metformin monotherapy: a systematic review and network meta-analysis. Diabetes Obes Metab 16(5): 433-442.

65. Monami M, Nardini C, Mannucci E (2014) Efficacy and safety of sodium glucose co-transport- 2 inhibitors in type 2 diabetes: a meta-analysis of randomized clinical trials. Diabetes Obes Metab 16(5): 457-466.

\begin{tabular}{l} 
Your next submission with Juniper Publishers \\
will reach you the below assets \\
- Quality Editorial service \\
- Swift Peer Review \\
- Reprints availability \\
- E-prints Service \\
- Manuscript Podcast for convenient understanding \\
- Global attainment for your research \\
- Manuscript accessibility in different formats \\
( Pdf, E-pub, Full Text, Audio) \\
- Unceasing customer service \\
Track the below URL for one-step submission \\
https://juniperpublishers.com/online-submission.php \\
\hline
\end{tabular}

